\title{
Intensity Modulated Radiotherapy of Two Simultaneous Neoplasms - Cervical Carcinoma and Breast Carcinoma: A Case Report with a Review of the Literature
}

\author{
Vaska Vassileva, Lena Marinova* and Viktor Petrov \\ Medical Oncology Clinic, Radiation and Metabolic Brachytherapy Department, UMHAT "Queen Joanna" \\ Sofia, Bulgaria
}

\begin{abstract}
Concomitant expression of two neoplasms- cervical carcinoma (CC) and breast carcinoma (BC) is a relatively rare pathology. The manifestation of synchronous primary neoplasms is a challenge for the treating team as it puts a number of questions about the healing strategy.

We present a 57-year-old patient after total laparohisterectomy with lymphatic pelvic dissection on the local advanced CC/IIIB clinical stage. Intensity-modulated radiotherapy (IMRT) in the small pelvis and the upper $2 / 3$ of the vaginal cuff with daily dose (DD) 1.8 Gy up to total dose (TD) 50.4 Gy combined with Cisplatin $\left(50 \mathrm{mg} / \mathrm{m}^{2}\right)$ once a week, was conducted. After 4 months from the diagnosis and complex treatment of CC, PET/CT establishes a second neoplasminvasive ductal carcinoma in the left mammary gland. After the breast-conserving surgery of $\mathrm{BC}$, we are currently conducting Deep Inspiration Breath-Hold (DIBH) Radiation Technique on the left breast with DD 2 Gy up to TD 50 Gy. After 1 month of pelvic RT completion, RT on the paraaortal lymph nodes with DD 1.8 Gy up to TD 50 Gy should be conducted.

The discussion focuses on the simultaneous expression of two or more neoplasms, their relationship with genetic and other unfavorable predisposing factors, as well as the expected survival after the complex treatment of the two invasive carcinomas, involving IMRT.

For the treatment of multiple malignancies, each case must be considered individually, ideally by a multidisciplinary team. If it is necessary to apply radiotherapy, the use of high-tech radiotherapeutic apparatus with the ability to perform modern radiotherapy techniques such as IMRT is required.
\end{abstract}

Keywords: Synchronous primary neoplasms, unfavorable predisposing factors, prognosis, complex treatment, intensity-modulated radiotherapy.

\section{INTRODUCTION}

Cervical carcinoma (CC) is the fifth most common cancer in women and the third leading cause of cancer mortality in women globally [1]. It is the leading cause of lethal outcome in women in developing countries and the third most common gynaecological carcinoma in the United States [2]. In Bulgaria the morbidity of 2017. reaches $13 \cdot 1 / 100,000$ and the mortality is $5.1 / 100,000$ [3]. Multiple primary malignancies (MPMs) are present when a patient is diagnosed with more than one primary malignancy and when each tumor is histologically unrelated to the others [4]. Concomitant expression of two neoplasms- cervical carcinoma and carcinoma of the mammary gland is a relatively rare pathology. The appearance of synchronous primary neoplasms is a challenge for the treating team as it puts a number of questions about the patient's healing strategy.

*Address correspondence to this author at the Medical Oncology Clinic, Radiation and Metabolic Brachytherapy Department, UMHAT "Queen Joanna" Sofia, Bulgaria; E-mail: rad_marinova@abv.bg

ISSN: 1929-2260 / E-ISSN: 1929-2279/21

\section{CLINICAL CASE}

This clinical case presents a 57 years old patient, after radical laparohisterectomy with pelvic lymph node dissection for cervical carcinoma (IIIB clinical stage in FIGO), with histological results moderately differentiated (G2) squamous carcinoma, extensive necrosis areas, multiple tumors embolis in lymph and blood vessels, perineural invasion; isthmus and uterine body with massive infiltration from the abovementioned carcinoma; without serosal infiltration; 12 nonmetastatic left pelvic lymph nodes, right pelvic lymph nodes-3 metastatic lymph nodes of 12 dissected lymph nodes. On 26.07.2021. the patient started postoperative intensity-modulated radiotherapy (IMRT) with VMAT technique in the pelvis and the upper $2 / 3$ of the vaginal cuff with daily dose (DD) $1.8 \mathrm{~Gy}$ up to total dose (TD) 50.4 Gy combined with Cisplatin $(50 \mathrm{mg} /$ m2) once a week (Figure 1) The patient experienced very well postoperative simultaneous radiochemotherapy (RT-Ch).

After 4 months from the diagnosis and complex treatment of CC, PET/CT establishes a second neoplasm in the left mammary gland. Quadrantectomy with axillary lymph nodes dissection of I and II levels 


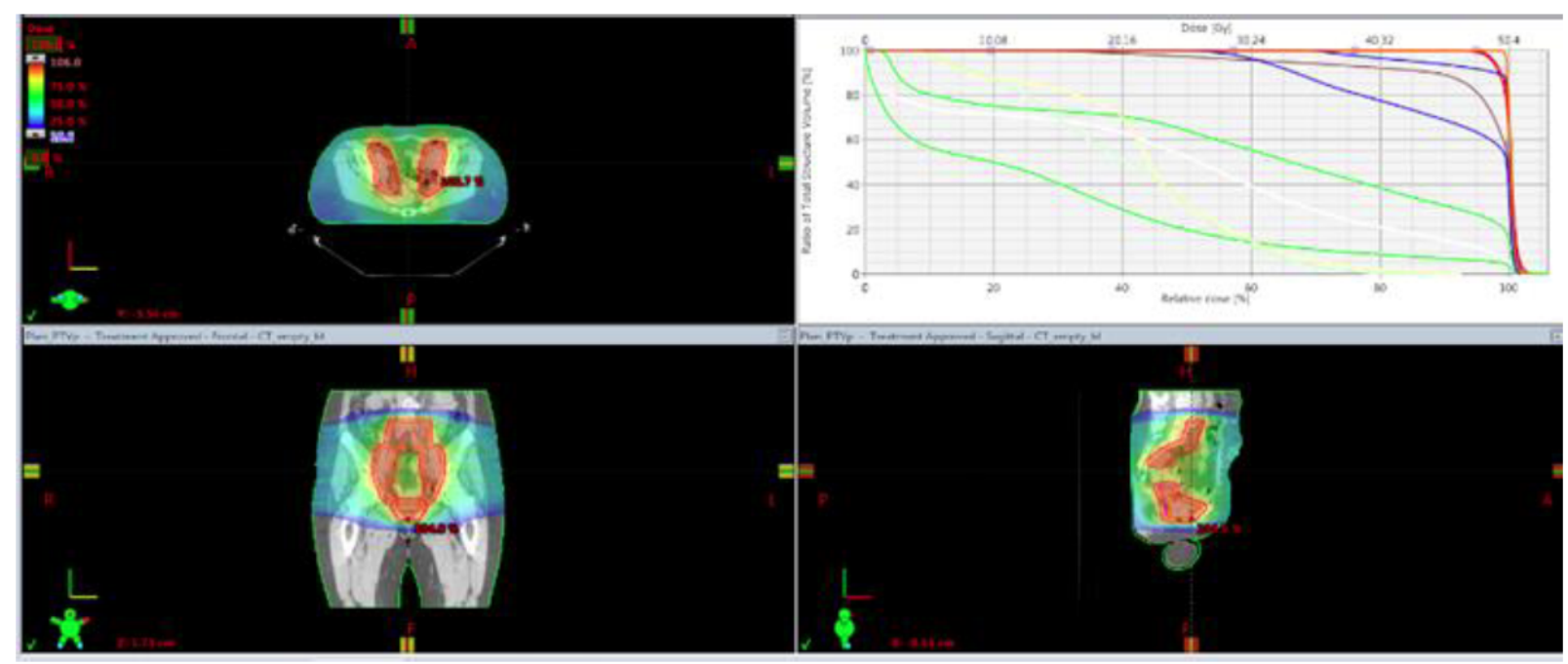

Figure 1: Postoperative intensity-modulated radiotherapy (IMRT) with VMAT technique in the pelvis and the upper 2/3 of the vaginal cuff with daily dose (DD) 1.8 Gy up to total dose (TD) 50.4 Gy combined with Cisplatin $(50 \mathrm{mg} / \mathrm{m} 2)$ once a week.

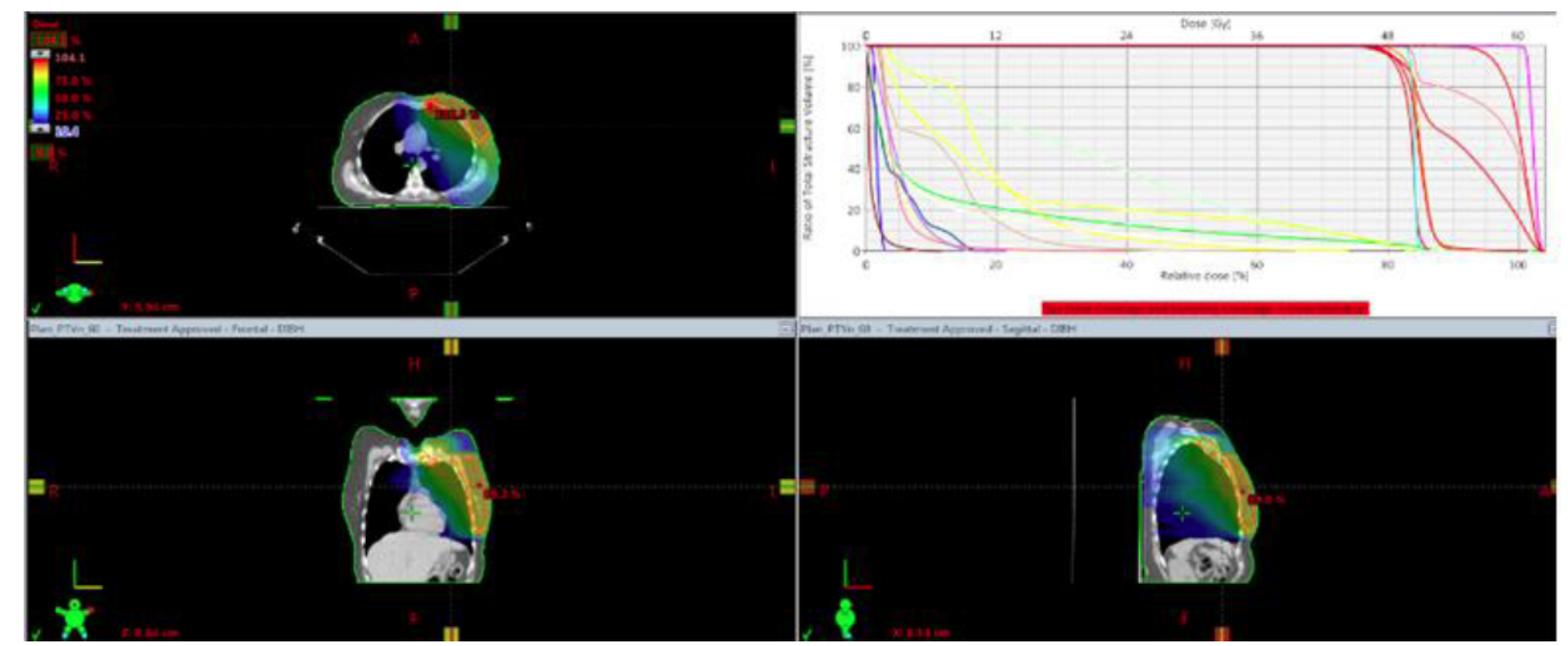

Figure 2: Deep Inspiration Breath-hold (DIBH) radiation technique by using volumetric modulated arc therapy (VMAT) with DD 2 Gy up to TD 50 Gy.

was carried out which revealed the following histological and immunohistochemical resultsmoderately differentiated invasive ductal carcinoma (G2); tumor with a maximum diameter of $16 \mathrm{~mm}, 10$ axillary lymph nodes without metastasis; estrogen receptor (ER) 2+; Progesterone receptor (PR) negativ; HER2 (1+) negativ. After breast-conserving surgery of $\mathrm{BC}$, the left mammary gland was irradiated with deep inspiration breath-hold (DIBH) radiation technique by using volumetric modulated arc therapy (VMAT) with DD 2 Gy up to TD 50 Gy (Figure 2). After 1 month of pelvic RT completion, RT on the paraaortal lymph nodes with DD 1.8 Gy up to TD 50 Gy should be conducted.

The pelvic and left breast radiotherapy was conducted with a weekly assessment of traceability of paraclinical indicators and strict monitoring of early radiation toxicity expression. The patient showed very good therapeutic tolerance without early radiation reactions from normal tissues and organs.

\section{DISCUSSION}

In the 1930s Warren and Gates [5] proposed the first working definition of multiple primary neoplasms (MPNs): (1) both tumors should be confirmed histologically as malignant; (2) each cancer must be anatomically separate and distinct; and (3) the second tumor must not be a recurrence or metastasis of first cancer. This means that tumours arise in other organs than the independent primaries, each tumour has to be histologically distinctive and the possibility of metastasis or recurrence must be excluded $[6,7]$. The 
mechanism of development of MPNs is unclear and likely multifactorial; identified risk factors include previous cancer treatment, smoking, diet, and genetic mutations [8]. The synchronous expression of breast and cervical carcinoma is a rare event, due to various unfavorable predisposing factors [9]. With the active application of the PET/CT scanners in order to strictly define the stage of the malignant tumors, the possibilities for detecting synchronous neoplasms have risen sharply [10]. The appearance of synchronous primary neoplasms is a challenge for the treating team as it puts a number of questions about the patient's healing strategy. This is a therapeutic dilemma in everyday clinical practice [11]. Causal mechanisms of their development include the following: (i) host factors - genetic (BRCA mutations, Li-Fraumeni syndrome), hormonal, prior cancer diagnosis and treatment exposures, (ii) lifestyle factors such as alcohol and tobacco use (risk factors for several cancer types), and (iii) environmental influences - geography (areas of increased radon exposure), pathogens (human papilloma virus or Epstein-Barr virus infections) and occupational factors [12-17]. Patients with multiple primaries have less aggressive malignancies, present at earlier stages, frequently have a strong family history of similar cancer, and their cancers tend to have indolent clinical behavior with longer survival rates, possibly related to genetic predisposition [14]. Synchronous genital tract neoplasms are rare but cause more clinical problems than a single neoplasm $[18,19]$. In the publication of Kenji Goto et al./2005, there are two synchronous cervical carcinomas with a different histological results (exocervical squamous cell carcinoma and endocervical clear cell adenocarnoma), in which Human Papilloma Virus (HPV) 18 only in the squamous cell carcinoma was found [20]. $4-17 \%$ of patients with breast cancer (BC) develop multiple primary neoplasias. The most frequent type of synchronous malignancy in patients with $B C$ is contralateral breast cancer $(63.3 \%$ of cases) followed by female genital organ cancer (13.4\% of cases) [6]. In the publication of L. Marinova et al. / 2015, an interesting and extremely rare clinical case of two synchronous tumors in the breast, namely invasive ductal carcinoma and primary breast osteosarcoma has been presented [21]. Most often diagnosed synchronous neoplasms are contralateral breast cancer and genital cancers, of which most common is cervical cancer [22]. Genetic factors (e.g., BRCA1, BRCA2) are seen as habitual risk factors for multiple primary tumors [23]. Published data indicate that age, as well as menopausal status at breast cancer diagnosis, are risk factors for the development of second cancer [24-26]. Studies in Japan and Italy estimated that $9 \%-11 \%$ of early gastrointestinal carcinomas develop other malignancies $[27,28]$. Fiveyear survival rates were higher for metachronous cancers $(95 \%)$ than for synchronous primaries $(59 \%)$ and single primaries (59\%) [14]. For the treatment of multiple malignancies, each case must be considered individually, ideally by a multidisciplinary team, accounting for the type and stage of each tumor, response to treatment, and the patient's overall health status [8]. In the present case, the familial history of the patient implies a high risk of malignant neoplasms as her mother had uterine cancer. Breast cancer is a socially significant, most commonly diagnosed neoplasm in women. In the current clinical case, as it is a I clinical-stage BC after a conservative breast surgery, no chemotherapy is required. For stage IIA $\mathrm{BC}$, the decision was to treat her with chemotherapy followed by postmastectomy radiation therapy due to multiple risk factors, including focal lymphovascular space invasion and 2 positive lymph nodes [29]. Breast-preserving surgery with subsequent high-tech radiotherapy has a great contribution to achieving very good therapeutic and cosmetic results [30]. Adjuvant left breast radiotherapy (ALBRT) for breast cancer can result in a significant radiation dose to the heart [31]. As the number of BCs survivors has increased, chronic sequelae of breast cancer RT has become more important [32]. Heart-sparing can be performed in three different ways in breast cancer radiotherapy: by seeking to keep the heart out of treated volumes (i.e. by prone position or specific breathing techniques such as deep inspiration breath-hold (DIBH) and/or gating), or by using modern radiation techniques like IMRT, volumetric modulated arc therapy (VMAT) or protons [33]. Deep Inspiration Breath-hold (DIBH) is a wellestablished radiation technique to achieve a significant cardiac dose reduction during adjuvant radiotherapy (RT) in left-sided breast cancer (Figure 2). A new linac system with an integrated surface scanner (SS) for DIBH treatments could easily be incorporated into the daily routine and is associated with significant dose reduction to the heart and ipsilateral lung [34].

\section{CONCLUSIONS}

Concomitant expression of two neoplasms- cervical carcinoma (CC) and breast carcinoma (BC) is a relatively rare pathology. The manifestation of synchronous primary neoplasms is a challenge for the treating team as it puts a number of questions about the healing strategy. The forecast is dependent on the histological results of the corresponding primary 
tumors, accounting for the type and stage of each tumor and the adequate complex treatment. For the treatment of multiple malignancies, each case must be considered individually, ideally by a multidisciplinary team. If it is necessary to apply radiotherapy, the use of high-tech radiotherapeutic apparatus with the ability to perform modern radiotherapy techniques such as IMRT is required.

\section{REFERENCES}

[1] Mayr NA, Small W, Jr. Gaffney DK. Decision Making in Radiation Oncology 2011; 2(22).

[2] Bermudez RS, Huang K, Hsu I-C. Handbook of EvidenceBased Radiation Oncology 2010; Chapter 29.

[3] Bulgarian National Cancer Register. University Specialized Hospital for Active Oncology Treatment, Tom XXVI 2020.

[4] Williamson CW, Paravati A, Ghassemi $M$, et al. Five Simultaneous Primary Tumors in a Single Patient: A Case Report and Review of the Literature. Case Rep Oncol 2015; 8(3): 432-438.

https://doi.org/10.1159/000440799

[5] Warren S, Gates O. Multiple primary malignant tumors: a survey of the literature and statistical study. Am J Cancer 1932; 16: 1358-1414.

[6] Lee J, Park S, Kim S, et al. Characteristics and survival of breast cancer patients with multiple synchronous or metachronous primary cancers. Yansei Medical J 2015; 56: 1213-1220.

https://doi.org/10.3349/ymj.2015.56.5.1213

[7] Filali K, Hedelin G, Schaffer P, et al. Multiple primary cancers and estimation of the incidence rates and trends. Eur $\mathrm{J}$ Cancer 1996; 32A: 683-690. https://doi.org/10.1016/0959-8049(95)00621-4

[8] Coleman MP. Multiple primary malignant neoplasms in England and Wales, 1971-1981. Yale J Biol Med 1986; 59: 517-531.

[9] Sharma DN, Chander S, Awasthy BS, Rath GK. Synchronous occurrence of carcinoma of the uterine cervix and of the breast. Eur J Surg Oncol 1999; 25: 547-548. https://doi.org/10.1053/ejso.1999.0695

[10] Padegaonkar A, Chadha P, Shetty A. A Rare Case of Synchronous Cervical and Breast Carcinoma. Indian Journal of Surgical Oncology 2018; 9(4): 622-623. https://doi.org/10.1007/s13193-018-0814-y

[11] Amer MH. Multiple neoplasms, single primaries, and patient survival. Cancer Manag Res 2014; 6: 119-134. https://doi.org/10.2147/CMAR.S57378

[12] Travis LB. The epidemiology of second primary cancers. Cancer Epidemiol Biomarkers Prev 2006; 15: 2020-2026. https://doi.org/10.1158/1055-9965.EPI-06-0414

[13] Vogt A, Schmid S, Heinimann K, et al. Multiple primary tumours: challenges and approaches, a review. ESMO Open 2017; 2: e000172.

https://doi.org/10.1136/esmoopen-2017-000172

[14] Amer MH. Multiple neoplasms, single primaries, and patient survival. Cancer Manag Res 2014; 6: 119-134. https://doi.org/10.2147/CMAR.S57378

[15] Mariotto AB, Rowland JH, Ries LA, et al. Multiple cancer prevalence: a growing challenge in long-term survivorship. Cancer Epidemiol Biomarkers Prev 2007; 16: 566-571. https://doi.org/10.1158/1055-9965.EPI-06-0782

[16] Calip GS, Law EH, Ko NY. Racial and ethnic differences in risk of second primary cancers among breast cancer survivors. Breast Cancer Res Treat 2015; 151: 687-696. https://doi.org/10.1007/s10549-015-3439-7
[17] Molina-Montes E, Requena M, Sanchez-Cantalejo E, et al. Risk of second cancers cancer after a first primary breast cancer: a systematic review and meta-analysis. Gynecol Oncol 2015; 136: 158-171.

https://doi.org/10.1016/j.ygyno.2014.10.029

[18] Lin C-K, Yu M-H, Chu T-W, Lai H-C. Synchronous occurrence of primary neoplasms in the uterus with squamous cell carcinoma of the cervix and adenocarcinoma of the endometrium. Taiwan J Obstet Gynecol 2006; 45(4): 336-9. https://doi.org/10.1016/S1028-4559(09)60255-2

[19] Yasui Y, Suzumori K, Yagami Y, Nakamura T. Squamous cell carcinoma of the endometrium coexistent with synchronous adenocarcinoma of the cervix. Gan No Rinsho 1987; 33(15): 1954-8.

[20] Goto K, Takeuchi Y, Yakihara A, Kotsuji F. Synchronous invasive squamous cell carcinoma and clear cell adenocarcinoma of the uterine cervix: a different human papillomavirus status. Gynecol Oncol 2005; 97(3): 976-9. https://doi.org/10.1016/j.ygyno.2005.03.027

[21] Marinova L, Hadjieva T, Kanchev E, Vicheva S. Synchronous primary mammary osteosarcoma and invasive breast cancer. A case report - Pathohistological and immunohistochemical analysis. Rep Pract Oncol Radiother 2015; 20(1): 72-76. https://doi.org/10.1016/j.rpor.2014.04.003

[22] Sas-Korczyńska B, Mituś JW, Kamzol W, et al. Synchronous malignancies in patients with breast cancer. NOWOTWORY J Oncol 2017; 67: 336-341. https://doi.org/10.5603/NJO.2017.0055

[23] Vogt A, Schmid S, Heinimann K, et al. Multiple primary tumours: challenges and approaches, a review. ESMO OPEN 2017; 2(2): e000172. https://doi.org/10.1136/esmoopen-2017-000172

[24] Schaapveld M, Visser O, Louwman MJ, et al. Risk of new primary nonbreast cancers after breast cancer treatment: a Dutch population-based study. J Clin Oncol 2008; 26: 12391246.

https://doi.org/10.1200/JCO.2007.11.9081

[25] Chen Y, Thompson W, Semenciw R, et al. Epidemiology of contralateral breast cancer. Cancer Epidemiol Biomarkers Prev 1999; 8: 855-861.

[26] Hislop TG, Elwood JM, Coldman AJ, et al. Second primary cancer of the breast: incidence and risk factors. $\mathrm{Br} \mathrm{J}$ Cancer 1984; 49: 79-85. https://doi.org/10.1038/bjc.1984.12

[27] Ikeguchi M, Ohfuji S, Oka A, et al. Synchronous and metachronous primary malignancies in organs other than the stomach in patients with early gastric cancer. Hepatogastroenterology 1995; 42: 672-676.

[28] Bozzetti F, Bonfanti G, Mariani L, et al. Early gastric cancer: unrecognized indicator of multiple malignancies. World $\mathrm{J}$ Surgery 2000; 24 : 583-587.

https://doi.org/10.1007/s002689910097

[29] Ebctcg. McGale P, Taylor C, et al. Effect of radiotherapy after mastectomy and axillary surgery on 10-year recurrence and 20-year breast cancer mortality: meta-analysis of individual patient data for 8,135 women in 22 randomised trials. Lancet 2014; 383: 2127-2135. https://doi.org/10.1016/S0140-6736(14)60488-8

[30] Marinova L, Petrova K, Evgeniev N. Radiotherapy after Breast-Preserving Surgery for Early Breast Cancer-Basic Principles and Our Experience. Austin J Med Oncol 2021; 8(1): 1058. https://doi.org/10.26420/austinjmedoncol.2021.1058

[31] Hayden AJ, Rains M, Tiver K. Deep inspiration breath hold technique reduces heart dose from radiotherapy for left-sided breast cancer. J Med Imaging Radiat Oncol 2012; 56(4): 46472.

https://doi.org/10.1111/j.1754-9485.2012.02405.x 
[32] Shah C, Badiyan S, Berry S, et al. Cardiac dose sparing and avoidance techniques in breast cancer radiotherapy. Radiother Oncol 2014; 112(1): 9-16. https://doi.org/10.1016/j.radonc.2014.04.009

[33] Duma M-N, Baumann R, Budach $W$, et al. Heart-sparing radiotherapy techniques in breast cancer patients: a recommendation of the breast cancer expert panel of the
German society of radiation oncology (DEGRO) Strahlenther Onkol 2019; 195(10): 861-871.

https://doi.org/10.1007/s00066-019-01495-w

[34] Hepp R, Ammerpohl M, Morgenstern C, et al. Deep inspiration breath-hold (DIBH) radiotherapy in left-sided breast cancer: Dosimetrical comparison and clinical feasibility in 20 patients. Strahlenther Onkol 2015; 191(9): 710-6. https://doi.org/10.1007/s00066-015-0838-y

(C) 2021 Vassileva et al.; Licensee Neoplasia Research.

This is an open access article licensed under the terms of the Creative Commons Attribution Non-Commercial License (http://creativecommons.org/licenses/by-nc/3.0/) which permits unrestricted, non-commercial use, distribution and reproduction in any medium, provided the work is properly cited. 